\title{
A Case Study of Colorfastness of Waterless Dyed Fabrics Sustainable for the Environment
}

\author{
Maddy Zitkus, Bre Lowe, Brianna Voss, Tanaijiah Fields, Sigourney Porter, and Ui-Jeen Yu \\ Illinois State University, Normal, IL, USA
}

Keywords: colorfastness, waterless dyed fabrics

In the fashion Industry there are high amounts of wastewater used in the production of textile products. The textile-dyeing sector is one of the world's most polluting industries and releases trillions of liters of chemically-tainted wastewater (Guzel \& Akgerman, 1999; Davies, 2016; Heida, 2019). Textile dyeing processes cause 17 to $20 \%$ of industrial water pollution, and the textile industry continues to cause environmental stress on water resources in many developing countries (Agrawal, 2015; Miah et al., 2013). If new waterless dyeing technologies are adopted on a large scale, the textile-dyeing sector could reduce water pollution significantly (Guzel \& Akgerman, 1999; Heida, 2019).

Waterless dyeing is a new dyeing process that requires no water. Instead, this waterless dyeing process takes $\mathrm{CO}^{2}$ to dye textile products (Zaidy et al., 2019; Zhang et al., 2016; Zheng et al., 2018). $\mathrm{CO}^{2}$ use for dyeing textiles is more sustainable for the environment and will save freshwater typically used to dye textiles (Hussain \& Wahab, 2018; Zheng et al., 2018). Traditional dyeing processes use large amounts of water, energy, and chemical additives to fix dye on the fibers (Hussain \& Wahab, 2018; Zheng et al., 2018). Using $\mathrm{CO}^{2}$ instead reduces the level of pollution and drastically decreases the number of chemicals used in textile dyeing (Hussain \& Wahab, 2018; Zheng et al., 2018). The process of waterless dyeing on fabrics provides a more sustainable way of production and contributes a huge impact on garments consumers wear today.

DyeCoo, ColorZen, and AirDye have developed waterless dyeing machines that eliminate the need to process chemicals and add water (Hepburn, 2015). Nike and Adidas have integrated waterless dye technologies into their product lines, but experts in the textile industry worry about cost and limitation issues (Hepburn, 2015). For example, the waterless dyeing machine does not work well when dyeing natural fibers (Jain, 2019). The quality of waterless dyeing and colorfastness of waterless dyed fabric need investigated to promote consumers' sustainable consumption of eco-friendly textile products.

Today's consumers are more likely to purchase apparel products produced in more environmentally-conscious, sustainable methods. Research on colorfastness of waterless dyed fabric could contribute to enhance consumers' knowledge and experience with waterless dyed textile and apparel products. Thus, the purpose of this study is to examine colorfastness of waterless dyed fabrics through AATCC standard test methods.

A waterless dyed pair of leggings, made from $79 \%$ recycled polyester and $21 \%$ elastane, was purchased for testing. The leggings' brand is one of the global sportswear apparel brands. Its care label suggests 'machine wash cold delicate cycle, do not tumble dry, line dry in the shade, do not iron, do not dry clean, do not use fabric softener, use mild detergent only, wash 
separately, do not allow wet garment to dry bundled.' The waterless dyed fabric was tested for the quality of its colorfastness using the following AATCC standard test methods: AATCC 15 Colorfastness to Perspiration, AATCC 82 Colorfastness to Crocking, AATCC 61 Colorfastness to Laundering, and AATCC 19 Colorfastness to Flat Abrasion (Frosting). Specimens were prepared by cutting fabric samples from the waterless dyed leggings. All colorfastness tests were conducted by following the AATCC standard test methods. Specimens for the colorfastness to crocking were not cut on the bias due to the limited amount of fabric. This was a variation from the standard test method.

ASTM D 4156 Standard Performance Specification for Women's and Girls' Knitted Sportwear Fabrics indicate the specification requirements for colorfastness are Class 4 minimum for shade change and Class 3 minimum for staining and wet crocking. According to AATCC 15 Colorfastness to Perspiration, evaluations using the Gray Scale for Color Change indicated noticeable shade changes with an average of 2.8 in warp and an average of 2.3 in filling. Evaluations using the Gray Scale for Color Staining indicated the waterless dyed specimen had no significant color staining/transfer on other fibers in the multi-fiber test fabric; all grades were above 3 .

For AATCC 8 Colorfastness to Crocking, the amount of color transferred from the specimen to the white test square was assessed by using the Gray Scale for Staining. Results indicate the dry test average was 3.5, while the average for the wet test was 1.8. Results indicate slight color transfer occurred during the dry crocking on the specimen and noticeable color transfer for the wet crocking.

For AATCC 61 Colorfastness to Laundering, test results indicate significant shade changes of the specimen after launderings with the average ratings of 2.8 for warp and 3.2 for filling. The waterless dyed specimens did not transfer staining on other fibers in the multi-fiber test fabric; all grades were above 3 . The waterless dyed specimens exhibited little to no color transfer on the multifiber test fabric in the colorfastness tests to perspiration and laundering. This means when washed with other fabrics, the color transfer among fabrics would be minimal.

Finally, for AATCC 119 Color Change Due to Flat Abrasion (Frosting), test results indicate significant color change on the specimen due to frosting with the average rating of 1.25, according to the Grayscale to Color Change.

Overall, test results indicate the waterless dyed fabric did not meet product specifications required for women's and girls' knitted sportwear fabrics category regarding colorfastness to perspiration, crocking, laundering, and frosting, mainly because of color change and/or staining issues. Consumers would have low satisfaction of colorfastness performance, especially if the waterless dyed garment was not cared for properly following the care instructions. Possible defects of the waterless dyed fabric consumers might experience would be color or shade change due to perspiration, color transfer from the waterless dyed fabric to another lighter colored fabric by surface contact and rubbing, color or shade change after repeated laundering, and color change in localized abrasive areas due to flat abrasion.

The waterless dyed fabric claim regarding good colorfastness properties could misconstrue consumers about its colorfastness quality and performance. More accurate 
information about colorfastness of waterless dyed fabrics should be provided to consumers for their wise choice in purchasing and consuming environmentally-conscious textile products. Additional textile testing, such as colorfastness to burnt gas fumes, dry-cleaning, light, chlorine bleach, and non-chlorine, should be conducted for more detailed information about the product's colorfastness. Further research is also suggested for waterless dyed fabrics with different fiber blends and finishing methods to improve colorfastness as well as to expand the use of sustainable waterless dyeing for the environment.

\section{References}

Agrawal, B. J. (2015, September). Supercritical carbon-dioxide assisted dyeing of textiles: An environmental benign waterless dyeing process. International Journal of Innovative Research and Creative Technology, 1(2), 201-205

Davies, N. (2016). The sustainability of waterless dyeing. AATCC Review, 16(1), 36-41.

Guzel, B., \& Akgerman, A. (1999). Solubility of disperse and mordant dyes in supercritical CO2. Journal of Chemical \& Engineering Data, 44(1), 83-85.

Heida, L. (2019). Can Waterless Dyeing Processes Clean Up the Clothing Industry?. https://e360.yale.edu/features/can_waterless_dyeing_processes_clean_up_clothing_indus try_pollution

Hepburn, S. (2015). Nike and Adidas show cautious support for eco-friendly dye technology. https://www.theguardian.com/sustainable-business/sustainable-fashionblog/2015/apr/24/nike-and-adidas-show-cautious-support-for-eco-friendly-dyetechnology

Hussain, T., \& Wahab, A. (2018). A critical review of the current water conservation practices in textile wet processing. Journal of Cleaner Production, 198, 806-819.

Jain, S. (2019). Waterless Dyeing. https://tohproblemkyahai.com/waterless-dyeing/

Miah, L., Ferdous, N., \& Azad, M. M. (2013). Textiles material dyeing with supercritical carbon dioxide (CO2) without using water. Chemistry and Materials Research, 3(5), 38-40.

Zaidy, S. S., Vacchi, F. I., Umbuzeiro, G. A., \& Freeman, H. S. (2019). Approach to waterless dyeing of textile substrates - use of atmospheric plasma. Industrial \& Engineering Chemistry Research, 58(40), 18478-18487.

Zhang, Y. Q., Wei, X. C., \& Long, J. J. (2016). Ecofriendly synthesis and application of special disperse reactive dyes in waterless coloration of wool with supercritical carbon dioxide. Journal of Cleaner Production, 133, 746-756.

Zheng, H., Zhong, Y., Mao, Z., \& Zheng, L. (2018). CO2 utilization for the waterless dyeing: Characterization and properties of Disperse Red 167 in supercritical fluid. Journal of CO2 Utilization, 24, 266-273.

Page 3 of 3

(c) 2020 The author(s). Published under a Creative Commons Attribution License (https://creativecommons.org/licenses/by/4.0/), which permits unrestricted use, distribution, and reproduction in any medium, provided the original work is properly cited.

ITAA Proceedings, \#77 - https: //itaaonline.org 